\title{
A LÓGICA DO SISTEMA CAPITALISTA E A PRÁXIS DOS PESCADORES ARTESANAIS DA COLÔNIA Z-16 DE CAMETÁ/PA
}

\author{
Raimundo Nonato Gaia Correa² \\ Fred Junior Costa Alfaia/UFPA ${ }^{3}$
}

\section{Resumo}

O objetivo deste artigo é analisar como as determinações do sistema capitalista se expressam na práxis dos pescadores artesanais da Colônia de Z-16 de Cametá/PA. A pesquisa pauta-se em revisões bibliográficas e entrevista semiestruturada. Os dados foram analisados pelo viés da análise de conteúdo sob a perspectiva do Materialismo Histórico-Dialético. Conclui-se que os pescadores artesanais, ao constatarem os negativos impactos gerados pela construção da Hidrelétrica de Tucuruí, desenvolvem uma práxis de reação e se organizam politicamente a partir da Colônia Z-16, embora, contraditoriamente, também afirmem interesses do sistema capitalista.

Palavras-Chave: Práxis; Pescadores Artesanais; Contradições entre capital e trabalho.

\begin{abstract}
The objective of this article is to analyze how the determinations of the capitalist system are expressed in the praxis of the artisanal fishermen of the Z-16 Colony of Cametá/PA. The research is based on bibliographic reviews and semi-structured interviews. The data were analyzed by the bias of content analysis from the perspective of Historical-Dialectical Materialism. It is concluded that artisanal fishermen, when verified the negative impacts generated by the construction of the hydroelectric plant of Tucuruí/PA, they developed a praxis of reaction and organized themselves politically from the Z-16 Colony, although, in a contradictory way, they had also affirmed capitalist interests.
\end{abstract}

Keywords: Praxis; Artisanal fishermen; Contradictions between capital and work.

\footnotetext{
${ }^{1}$ DOI: https://doi.org/10.22409/tn.15i28.p9645

${ }^{2}$ Mestrando do Programa de Pós-Graduação em Educação e Cultura (PPGEDUC) vinculado à Universidade Federal do Pará, Campus de Cametá. Graduado em Pedagogia pela mesma instituição. E-mail: r.nonatog@hotmail.com.

${ }^{3}$ Mestre em Educação pela Universidade Federal do Pará. Docente da Faculdade de Educação da UFPA, Campus de Cametá. E-mail: fredparaense@yahoo.com.br.
} 


\section{INTRODUÇÃO}

No presente texto apresentamos e discutimos alguns resultados de pesquisa sobre a práxis de trabalhadores ligados à Colônia de Pescadores Artesanais Z $\mathrm{Z}-16^{3}$, município de Cametá/PA ${ }^{4}$, objetivando responder às seguintes questões: Quais as implicações da criação da Usina Hidrelétrica de Tucuruí na práxis dos pescadores artesanais ligados à Colônia de Pescadores Z-16 de Cametá/PA? Como as determinações do sistema capitalista se expressam nas ações e projetos da Colônia de Pescadores Z-16 de Cametá/PA?

Metodologicamente, a pesquisa pauta-se em revisões bibliográficas e pesquisa de campo, além do uso da entrevista semiestruturada (PÁDUA, 2012) junto a dois membros da direção da Colônia Z-16 e dois pescadores artesanais filiados na Entidade ${ }^{5}$. Os dados foram analisados pelo viés da análise de conteúdo ${ }^{6}$, sob a perspectiva do Materialismo Histórico-Dialético, permitindo a explicação dos fenômenos sociais a partir do movimento de ascensão da aparência à essência, conforme nos orienta Kosik (1976).

Em termos estruturais, duas seções constituem este trabalho. Numa primeira, apresentamos reflexões sócio-históricas acerca dos impactos ambientais e sociais causados a partir da criação da Usina Hidrelétrica de

\footnotetext{
3"Embora o termo colônia possa suscitar a imagem de um coletivo de pescadores vivendo da pesca à margem de um rio, a Colônia de Pescadores Artesanais Z-16 é bem mais que isso. Ela constitui-se na entidade representativa de classe desses sujeitos, reunindo 15.000 associados de diferentes comunidades do município cametaense, com sede na Travessa Porto Pedro Teixeira, $n^{\circ}$ 165, bairro de Brasília, cidade de Cametá" (RODRIGUES, 2012, p. 31). Fundada na década de 1920, esta entidade só recentemente (início dos anos 1990) passou a ser conduzida por gestores que se constituem pescadores artesanais, uma vez que desde sua fundação "[...] não estava sob a gestão dos pescadores, mas sim sob os auspícios de sujeitos não pescadores ligados aos interesses das oligarquias locais [...]" (ibidem, p. 257).

${ }^{4}$ Segundo Rodrigues (op. cit., p. 21-23), o município de Cametá, Estado do Pará, "[...] segundo - IBGE (2010), pertence à mesorregião do nordeste paraense e à microrregião Cametá, apresenta uma área correspondente a $3.122 \mathrm{~km}^{2}$. Limita-se ao norte com o município de Limoeiro do Ajuru; ao sul, com o de Mocajuba; a leste, com o de Igarapé-Miri; e a oeste, com o de Oeiras do Pará. Ainda segundo o (IBGE, 2010), o município cametaense apresenta uma população de 110.323 habitantes, dos quais 47.984 encontram-se na zona urbana e 62.339 na zona rural. Trata-se de um município com contingente rural maior do que o urbano. Com relação aos pescadores artesanais nesse município, eles estão presentes em um total de 122 localidades, com 523 comunidades cristãs, inseridas nas ilhas de Cametá, o que ordenou inclusive a própria organização administrativa dos pescadores".

${ }^{5}$ No corpo do texto serão identificados como "Dirigente A" e "Dirigente B"; "Pescador A" e "Pescador B".

${ }^{6}$ Para o desenvolvimento das análises a partir da Análise de Conteúdo tomamos as orientações de Bardin (1997).
} 
Tucuruí - UHT e a formação da atividade consciente objetiva ${ }^{7}$ dos pescadores artesanais ligados à Colônia de Pescadores Artesanais Z-16 de Cametá, estado do Pará. Numa segunda seção, abordamos, a partir de dados empíricos em correlação com questões teóricas, formas de expressão de determinações constitutivas do sistema do capital no contexto da Colônia Z-16 e as implicações disso na práxis dos pescadores artesanais. Por fim, apresentamos as considerações finais.

\section{A CONSTRUÇÃO DA UHT E ATIVIDADE CONSCIENTE OBJETIVA DOS PESCADORES ARTESANAIS DA COLÔNIA Z-16 DE CAMETÁ/PA}

A Usina Hidrelétrica de Tucuruí - UHT (1974-1985), foi construída "[...] para atender às demandas de grandes projetos industriais que se instalavam na região Norte, como o Complexo Industrial do Alumínio, em Vila do Conde, e a ALBRÁS e ALUNORTE, em Barcarena-PA" (RODRIGUES, 2012, p. 219). Os chamados "grandes projetos" são resultados das políticas desenvolvimentistas impostas pelos governos do Regime Militar (1964-1985) para a Amazônia Brasileira. Entretanto, o planejamento e a execução dessas obras não foram submetidos à consulta popular na região sobre os possíveis impactos.

Nesse contexto, a UHT, como uma das políticas de modernização autoritária, trazia consigo o discurso do desenvolvimento regional, sobretudo porque todos os municípios da Região do Baixo Tocantins ${ }^{8}$ seriam atendidos com redes de energia elétrica, e assim

[...] junto às camadas populares da região construía-se o saber de que sua implantação traria o desenvolvimento, implicando melhorias nas áreas da educação, da saúde, da geração de emprego e renda, principalmente para os ribeirinhos que

\footnotetext{
${ }^{7}$ Referenciando-nos em Vázquez (2007), entendemos a categoria práxis como atividade consciente objetiva e, por isso, especificamente humana. Segundo esse autor "para que se possa falar em atividade humana é preciso que se formule nela um resultado ideal, ou fim a cumprir, como ponto de partida, e uma intenção de adequação, independentemente de como se plasme, definitivamente, o modelo ideal originário. [...] E o resultado é uma nova realidade, que subsiste independentemente do sujeito ou dos sujeitos concretos que a engendraram com sua atividade subjetiva, mas que, sem dúvida, só existe pelo homem e para o homem, como ser social" (223-227).

${ }^{8}$ Conjunto de municípios do nordeste paraenses banhados pelo Rio Tocantins: Mocajuba, Igarapé-Miri, Oeiras do Pará, Limoeiro do Ajuru e Cametá.
} 
habitavam o rio Tocantins, com suas ilhas, igarapés e furos (ibidem, p. 219).

Todavia, esse discurso não passou de um instrumento ideológico capaz de conseguir o consenso na região, uma vez que, concluída a obra, seus municípios passaram a conviver com os negativos impactos que interferiram no próprio modo de seus habitantes produzirem suas existências, pois

[...] ao longo dos anos pós-construção da barragem, os pescadores artesanais foram verificando a diminuição de pescado, o empobrecimento ainda mais das comunidades e a perda de seus valores culturais, de sua identidade (ibidem, $\mathrm{p}$. 221).

Em Cametá não foi diferente. Todavia, nas comunidades ribeirinhas os pescadores artesanais que aí permaneceram, mesmo diante da diminuição do pescado, dentre outras negativas impostas pela construção da Hidrelétrica de Tucuruí, passaram a se organizar em função da busca de formas de garantir sua sobrevivência e atendimento aos seus interesses políticos e econômicos. Este fato revela-se quando os pescadores assumiram a administração da Colônia Z-16 e passaram a planejar as linhas de atuação, uma vez que, desde a sua criação na década de 1920 , era dirigida por representantes das oligarquias cametaenses (RODRIGUES, 2012).

Segundo Rodrigues (ibidem, p. 221), pode-se afirmar que esses trabalhadores, à medida que perceberam "[...] a realidade advinda com a construção da Hidrelétrica de Tucuruí, constatando a falta de pescado e o desequilíbrio total no cotidiano dos pescadores", desenvolveram um saber constatativo diante da realidade, não ficando, contudo, tão somente nessa perspectiva de constatação, pois passaram a interferir "[...] na realidade ao denunciar o culpado pelo desequilíbrio, instituindo um posicionamento político contrário ao propugnado pelo capital, qual seja o de que a construção da hidrelétrica melhoraria a qualidade de vida dos pescadores", desenvolvendo um saber performativo, agindo sobre a realidade de forma política.

A partir de então, a Colônia Z-16 passou a ser um instrumento de organização dos pescadores artesanais de Cametá, inclusive desenvolvendo 
ações alternativas aos impactos da construção da UHT, conforme acima mencionado. Nessa perspectiva, destaca-se a criação dos Acordos de Pesca: ${ }^{9}$

[...] uma forma que nós encontramos né, para que a gente pudesse garantir algumas espécies, garantir também com que a pesca de uma vez por todas não seja acabada, digamos assim né, por isso nós damos muita importância na questão dos acordos, pra gente equilibrar essas questões do ambiente (DIRIGENTE "A").

Os Acordos de Pesca foram criados nas comunidades de pescadores artesanais do município de Cametá sob a perspectiva da preservação ambiental, havendo um cuidado no sentido de coibir a chamada pesca predatória, isto é, aquela prática pesqueira que se vale de determinados instrumentos, como o puçáto ou as malhadeiras com malha fina (malhas pequenas) capazes de capturar o pescado miúdo (pequeno), impedindo dessa forma a sua reprodução.

Barra (2013) explica que os Acordos de Pesca constituem-se basicamente na autogestão dos recursos pesqueiros pelas próprias comunidades de pescadores artesanais.

[...] um grupo de pescadores controla o acesso e o uso de um território pesqueiro bem definido, ou melhor, os acordos de pesca exprimem regras que regulam 0 uso do recurso pesqueiro definidas por membros da comunidade ou grupos de usuários locais (p. 74).

Segundo um dos entrevistados, a prática dos Acordos de Pesca "[...] foi uma forma mais aprimorada de educar os pescadores para a questão da preservação do meio ambiente, para evitar a extinção do pescado e ter uma produção mais qualificada no município" (DIRIGENTE "B", grifo nosso).

Se por um lado os Acordos de Pesca revelam resistência aos impactos ambientais e às múltiplas carências do pescado na região, por outro, induzem a uma compreensão unilateral do problema, visto que os pescadores se

\footnotetext{
${ }^{9}$ Regulamentado conforme Instrução Normativa $n^{\circ} 29,31$ de dezembro de 2002 do Instituto Brasileiro do Meio Ambiente e dos Recursos Naturais Renováveis - IBAMA.

${ }^{10}$ Segundo Rodrigues (2012, p. 141), "O puçá é uma "Grande rede de malha fina, chega a 1.300 metros. Serve para fazer grandes bloqueios e arrasta o fundo do rio. Pega tudo [...]". Segundo a Revista Cametá (2004), com esse tipo de rede "pega tudo", há necessidade da extinção desse material, sendo sua existência decorrente das "[...] relações patronais e políticas que se estabeleciam [no município de Cametá] - muitos eram pequenos empresários com esse tipo de material que precisa de uma turma de pelo menos 80 pessoas".
} 
percebem como sujeitos da causa e efeito dos fenômenos advindos da construção da Usina Hidrelétrica de Tucuruí e não percebem os impactos ambientais e as carências como efeito dos interesses capitalistas.

Movidos pela propagação de ideias convenientes aos interesses dominantes, os pescadores artesanais reproduzem a crítica ingênua de sua realidade social conforme ilustra a posição do entrevistado:

Eu acredito que isso aí [falta de peixe] é uma falta de conscientização que tá faltando para nós em todas as comunidades. E aí, o que motiva isso, o ponto principal é esse, é o povo se conscientizar pra não fazer as coisas indevidas (PESCADOR “A").

Nas palavras de Marx e Engels (2007, p. 78), diríamos que:

Os indivíduos que formam a classe dominante possuem, entre outras coisas, também uma consciência e, por conseguinte, pensam; uma vez que dominam como classe e determinam todo o âmbito de um tempo histórico, é evidente que o façam em toda a sua amplitude e, como consequência, também dominem como pensadores, como produtores de ideias, que controlem a produção e a distribuição das ideias de sua época, e que suas ideias sejam, por conseguinte, as ideias dominantes de um tempo.

Isto posto, entendemos, entretanto, que não basta tão somente educar, quando a realidade que os pescadores artesanais vivenciam necessita muito mais do que isso. Assim, o educar para preservar deve ser acompanhado pelo educar para combater, conhecendo as determinações dos problemas enfrentados. Ademais, antes dos Acordos de Pesca como alternativas à diminuição do pescado por conta da construção da UHT, os cuidados com a preservação ambiental "eram práticas rotineiras na vida dos pescadores, que cuidavam de selecionar, por exemplo, o tipo de rede para o tamanho de peixe a ser pescado, a fim de se garantir a sempre reprodução" das espécies (RODRIGUES, op. cit., p. 233).

A perspectiva do educar se esvaece quando observamos que, historicamente, os pescadores artesanais já entendiam a necessidade de se preservar o meio ambiente, no sentido de tornar as suas práticas pesqueiras adequadas à manutenção da abundância do pescado. Daí entenderem que "onde tem os Acordos de Pesca é pra melhorar, porque onde não é [onde não 
existe 0 acordo] [...] você coloca uma malhadeira no seu porto, você não pega nem um peixe pra uma criança" (PESCADOR "B").

Não se pode negar que os Acordos de Pesca contribuíram para a preservação das condições mínimas de reprodução das espécies, o que possibilitou/possibilita o aumento da circulação de peixes nos rios da região. Mas não se pode deixar de considerar que esses acordos encontraram as bases de sustentação nas próprias experiências dos pescadores, já que muito antes buscavam pescar, no cotidiano de suas práticas laborativas, dentro das necessidades de uso, evitando agredir o ambiente que Ihes fornecia a existência.

A questão que se coloca, pois, é que existe relação entre os impactos ambientais na região e a construção da UHT, conforme corrobora o Dirigente "A", para o qual,

[...] depois da construção da barragem de Tucuruí, muitas espécies desapareceram e deixou, digamos assim, um débito com a população, principalmente com a pesqueira né, então a gente não pode ficar de braços cruzados né, a gente procurou algum mecanismo pra que a gente possa tá preservando isso (DIRIGENTE "A").

Nota-se, nesta assertiva, certo conhecimento por parte do informante da relação macro entre os fenômenos (impactos ambientais e UHT), porém se confirma a estratégia dos Acordos de Pesca como ação de preservação e manutenção das condições de reprodução do pescado, mas a origem do problema e a lógica que sustenta a criação de novas usinas hidrelétricas na Amazônia continua. Os Acordos de Pesca, por um lado, acabam sendo formas de adaptação às múltiplas carências e manutenção das poucas espécies que ainda restam. Neste contexto, não representam a negação do fenômeno gerador das múltiplas carências estabelecidas pela contradição do capital, uma vez que a degradação das condições naturais (falta de espécies de pescado, falta de qualidade da água, etc.) está mantida.

Os Acordos de Pesca, por outro lado, também representam a reafirmação do homem (classe trabalhadora) ao espaço, à terra, aos elementos da natureza, à moradia, ao trabalho, à cultura, às relações interpessoais, ou seja, constituem a reestruturação de sua identidade histórico-social, de modo que a objetividade capitalista, por mais que imponha múltiplas necessidades às 
subjetividades, não consegue produzir a negação absoluta da identidade dos trabalhadores, que se faz resistente nas suas formas de vida e trabalho.

Os Acordos de Pesca são construções da práxis dos pescadores artesanais, da reação à objetividade dominante capitalista, mas essa construção se dá sob relações contraditórias de interesses dos pescadores artesanais e do capital. Assim, mesmo tendo criado os Acordos de Pesca, os pescadores artesanais da Z-16 precisam submetê-los ao reconhecimento legal do Estado capitalista que legitima as práticas desses Acordos.

Observa-se que a práxis desses sujeitos não está condicionada somente à relação homem-natureza, mas à nova relação que se estabelece, homem-natureza-Estado. Nessa perspectiva, a pesquisa revela-nos que além da legalização de suas ações, a Colônia Z-16 vê-se desafiada a lutar por políticas sociais no âmbito do Estado como forma de fortalecimento organizacional.

Uma dessas políticas sociais é o chamado seguro defeso ${ }^{11}$ que, a partir de meados dos anos de 1990, torna-se acessível aos pescadores artesanais filiados à Colônia Z-16 por meio de um processo de lutas sociais. Na ótica dos entrevistados o seguro defeso "[...] tem ajudado sim, muito, na qualidade de vida" (DIRIGENTE "B"), o que nos mostra que essa política se insere no contexto da Z-16 sob a mediação ideológica da qualidade de vida, que passa a fazer parte do discurso social desses trabalhadores, os quais visualizavam o seguro defeso como forma de lhes garantir renda.

Ainda segundo o entrevistado Dirigente "B", se for feita uma análise das condições de vida dos pescadores há cerca de vinte anos, período anterior ao seguro defeso, e compararmos com a sua condição de vida atual,

você vê que tem um diferencial muito grande. [...] as moradas do pescador [...] eram quase padronizadas; uma casinha de madeira simples, tinha lá uma parede de miriti, sempre era coberto com palhas; em vez de ter um trapiche lá, ele tinha um miritizeiro que ele colocava lá pra dar acesso da beira-mar até a casa dele. Seu meio de transporte era o casco à vela que the transportava até a cidade [...].

\footnotetext{
${ }^{11}$ Recurso financeiro fornecido pelo Governo Federal, para que, no período de reprodução dos peixes, de novembro a fevereiro, não se entrasse nos rios para a pesca de alta produção, destinada ao mercado consumidor, senão para consumo próprio.
} 
Aparentemente, observa-se que houve certo avanço qualitativo na vida dos pescadores artesanais, mas com um olhar mais crítico, percebe-se, contraditoriamente, a inserção desses sujeitos na lógica de reprodução do capital pela via do consumo. De fato,

[...] não se pode imaginar um sistema de controle mais inexoravelmente absorvente [...] do que o sistema do capital globalmente dominante, que sujeita cegamente aos mesmos imperativos a questão da saúde e do comércio, a educação e a agricultura, a arte e a indústria manufatureira, que implacavelmente sobrepõe a tudo seus próprios critérios de viabilidade [...] sempre a favor dos fortes e contra os fracos. (MÉZÀROS, 2011, p. 96)

Assim, a produção da sensação de um falso "bem-estar" e o desejo consumista inserem esses trabalhadores na lógica de mercado: "Lá na casa, onde o pescador tá filiado, ele e a esposa, ele consegue levantar durante o ano, através do seguro, mais de cinco mil reais" (DIRIGENTE "B"). Ou seja, essa sensação de "bem-estar" pode acabar por obstruir a percepção da necessidade do acesso a outras políticas sociais (saúde, educação, segurança e etc.), na medida em que o entrevistado destaca a ascensão econômica e a aquisição de bens como aspecto transformador da realidade social dos pescadores.

A pesquisa revela-nos que, embora a práxis dos pescadores tenha produzido, ao longo da história, resistência aos impactos ambientais, culturais, econômicos, sociais e políticos causados pela construção da UHT, as políticas assistencialistas do Estado contribuem para uma relativa estabilidade nos conflitos de classes mediante a inserção da classe trabalhadora na lógica consumista e na realização pessoal em detrimento questões mais abrangentes como a luta pela educação de qualidade no campo, do atendimento à saúde no campo, da segurança, do lazer etc. 


\section{A EXPRESSÃO DA LÓGICA DO CAPITAL NOS PROJETOS/AÇÕES DA COLÔNIA DE PESCADORES ARTESANAIS Z-16 DE CAMETÁ}

Nesta seção, detemo-nos na análise de ações ou projetos que a Colônia Z-16 desenvolve tanto do ponto de vista da formação quanto no que tange ao auxílio financeiro para atividades produtivas do pescador artesanal. Inicialmente, vamos analisar o segundo caso.

Pontuamos, de imediato, que o acesso às políticas de financiamento de atividades produtivas do pescador artesanal se dá por meio de empréstimos bancários, os quais Ihes são acessíveis mediante projetos formulados pela Z16 em parceria com determinado banco. Mas também há projetos que fazem parte de políticas sociais do Estado de incentivo à pequena produção familiar, como é o caso do Programa Nacional de Fortalecimento da Agricultura Familiar (Pronaf). Contudo, todo empréstimo bancário possui taxas de juros de financiamento e que, no caso do não pagamento por parte do tomador, causam situações de inadimplência e bloqueio de crédito.

Do ponto de vista da percepção por parte dos pescadores artesanais ligados à Colônia Z-16 da importância ou não das políticas de financiamento bancário da produção, o entrevistado DIRIGENTE "A" considera que: "[...] é muito importante né, porque devido ao crédito eles podem melhorar lá na sua localidade, comprar o seu barquinho de pesca, podem melhorar lá o seu terreno; isso melhora muito a economia familiar".

Nessa mesma perspectiva corrobora o entrevistado PESCADOR "A", falando-nos acerca da importância do acesso ao PRONAF $B^{12}$ : "[...] a gente tem necessidade todo tempo, e ele trouxe um benefício pra nós porque a gente conseguiu alguma coisa que a gente não tinha [...]; com esse financiamento nós conseguimos alguma coisa".

Novamente vemos que o pescador artesanal da Colônia Z-16 visualiza a política de crédito bancário enquanto uma possibilidade de atendimento a suas carências materiais imediatas não se consubstanciando em ações que visem à transformação radical da sociedade em proveito de uma perspectiva

\footnotetext{
${ }^{12}$ O Pronaf Grupo "B" é uma linha de microcrédito rural que disponibiliza recursos de pequenos valores para pequenos investimentos em atividades agrícolas e não agrícolas no meio rural tais como: compra de pequenos animais, artesanato, implementos para fabricação de alimentos, caixas de abelha, construção de poços para a criação de peixes, etc.
} 
revolucionária. Segundo Rodrigues "[...] o capital cria formas conjunturais de garantir a sobrevida do trabalhador, sem mudar as condições estruturais que Ihe garantem a dominação política, social, cultural e econômica, acima de tudo" (op. cit., p. 85), percebe-se nas falas dos pescadores entrevistados a assimilação da ordem social constitutiva do capital sem indicarem as contradições dessa aparente "benfeitoria".

Os pescadores artesanais não percebem que, para o capital, todos são tratados como consumidores, isto é, não interessa se a atividade produtiva de quem tomou o empréstimo tenha dado certo ou fracassado, essa questão é indiferente ao banco, pois o que importa é o pagamento das parcelas e juros em dia. Por outro lado,

[...] quando tem inadimplência, o banco, ele se resguarda em fazer o financiamento, porque ninguém quer perder dinheiro né? Então, ele só vai colocar esse crédito à disposição [do pescador] quando a instituição [a Colônia Z-16] apresenta uma proposta de investimento seguro [...] (PESCADOR "A", grifos nossos).

Nesse caso, observa-se a inserção do pescador à lógica capitalista, via spread bancário, quer dizer, projetos dessa natureza acabam por expor o pescador à lógica consumista e dependente da movimentação de desenvolvimento de capital (relação capital-produto-capital). Marx (2010, p. 46) recorre às palavras de Smith para ressaltar que

O único motivo que determina o possuidor de um capital a empregá-lo, seja na agricultura, seja na manufatura, ou no ramo particular do comércio por atacado (em gros) ou varejista (em détail), é o ponto de vista do seu próprio lucro. Nunca lhe vem à mente calcular quanto trabalho produtivo todas essas diversas espécies de aplicação põe em atividade, ou quanto é acrescentado em valor ao produto anual das propriedades agrícolas e [ao produto anual] do trabalho de seu país.

O pescador que antes tinha uma práxis econômica simples (mercadoria-capital-mercadoria), por meio da comercialização do excedente de sua produção, agora inaugura uma práxis econômica complexa (capitalmercadoria-capital) no ciclo de contrair empréstimo bancário-produzir e venderquitar a dívida e juros contraídos, atendendo assim as exigências políticas, econômicas e burocráticas do mercado. Segundo Bogo $(2008$, p. 12) é através 
do mercado que os agentes do capital, tais como os bancos, "se 'intrometem' na vida privada e coletiva dos seres humanos e [...] vão desmanchando todas as resistências. [...] é com ele e graças a ele que a mais-valia, na produção, ganha sentido, e se transforma em novas aquisições e investimentos".

[...] então a Colônia apresenta sempre projetos assim [projeto seguro], uns ele é entendido [pelas agências financiadoras] assim como projetos seguro; outros não. Então o projeto que a gente já apresentou de forma segura foi o DRS Desenvolvimento Rural Sustentável que seria um crédito direcionado para o pescador fazer os seus poços de criação. Esse projeto foi avaliado como positivo porque todos pagaram seus financiamentos e já está sendo financiado novamente (DIRIGENTE "B". Grifos nossos).

Um projeto é avaliado como seguro pelos bancos quando oferece possibilidades de retorno imediato que garanta o pagamento dos empréstimos contraídos. Não há a preocupação com a relevância social, isto é, com os benefícios que tais projetos podem trazer para a melhoria das condições de vida e trabalho dos sujeitos nele envolvidos, ficando claro o objetivo de inserção dos pescadores artesanais no movimento de reprodução do capital.

Para o capitalista, a aplicação mais útil do capital é aquela que Ihe rende, com igual segurança o maior ganho. Esta aplicação não é sempre a mais útil para a sociedade; a mais útil é aquela que é empregada para extrair benefícios (Nutzen) das forças produtivas da natureza (MARX, op. cit., p. 46).

O que aparentemente pode ser visto como uma política de auxílio aos pescadores artesanais, na essência (KOSIK, op. cit.) fortalece a consolidação da sociedade em classes, movimenta o capital e aliena o trabalho dos pescadores à lógica lucrativa do capitalismo e dificulta o desenvolvimento de uma postura de contestação ao projeto do grande capital.

Da mesma forma, a pesquisa revela-nos que os projetos deflagrados pela Colônia Z-16 seguem essa mesma lógica, isto é, insuficiência de conteúdo crítico e conotação imediatista e pragmática. Assim, é que se desenvolveu um laboratório de produção de alevinos a fim de fornecê-los aos pescadores para a criação de peixes mediante a escavação de poços.

[...] então, essas coisas que a gente trabalha é uma alternativa [...]. Quando a pessoa trabalha com a piscicultura, tem ali as suas casas de mel que ele vai cuidar disso, e a gente [Colônia 
Z-16] vai ajudar eles a fazer isso. Ano passado por exemplo, nós vendemos quatro toneladas de mel (DIRIGENTE "A").

Ainda que se trate de projetos que contribuem para o sustento das famílias pescadoras, consideramos que se trata de ações que primam pelo aspecto utilitarista da práxis humana (VÁZQUEZ, op. cit.), voltadas para o saber fazer, para o que rapidamente pode gerar dividendos econômicos, esvaziando do resultado do trabalho o sentido de valor de uso e instaurando o valor de troca. No dizer de Marx (2002, p. 63),

quem com seu produto, satisfaz a própria necessidade gera
valor de uso, mas não mercadoria para criar mercadoria, é
mister não só produzir valor de uso, mas produzi-lo para
outros, dar origem a valor de uso social [...]. O produto, para se
tornar mercadoria, tem de ser transferido a quem vai servir
como valor de uso por meio da troca.

Dessa forma, observa-se uma busca por processos de industrialização em que a maximização da produção e a capacidade de gerar retornos imediatos são princípios norteadores das ações: "Nós construímos uma fábrica de palmito, aí faz o manejo do açaí no final do verão, quando termina o açaí, a pessoa fode fazer o manejo, aí tira o palmito e já leva pra fábrica. [...] teve muito produtor que melhorou ali, conseguiu ganhar seu dinheirinho" (DIRIGENTE "A").

São ações que não ensejam uma reflexão sobre as condições materiais de existência dos pescadores artesanais e, assim, não permitem compreender o porquê desse coletivo de trabalhadores, desassistidos de políticas que Ihes possibilitem melhorias efetivas de suas condições de vida e trabalho, serem obrigados a buscar na informalidade as condições de reprodução da existência.

Nessa mesma perspectiva de esvaziamento de conteúdo crítico, a Colônia Z-16 também desenvolve ações na área da formação das quais destacamos algumas: o Pescando o saber que possibilitou aos pescadores artesanais analfabetos, por meio de processo de letramento, o conhecimento da linguagem escrita padrão; os projetos Gestão Compartilhada de Recursos pesqueiros e Formação de Agentes Ambientais Voluntários que se mostram relevantes pois promoveram debate intersetorial sobre a importância da preservação ambiental para a garantia da reprodução das espécies de peixes e 
da pesca na região, bem como a formação de sujeitos pescadores artesanais para atuarem diretamente no processo de sensibilização da população ribeirinha acerca dessa importância, respectivamente; o projeto Pescador Transformador que, por meio do cursinho pré-vestibular em parceria com a UFPA $^{13}$, possibilitou 0 acesso de jovens filhos de pescadores artesanais ao ensino superior; e as aulas de informática do projeto Inclusão Digital que colocaram pescadores artesanais de diversas idades em contato com as Novas Tecnologias de Informação e Comunicação.

No plano imediato, observamos que as ações e projetos desenvolvidos pela Colônia de Pescadores Z-16, em termos formativos e produtivos, buscam preencher a lacuna deixada pelo Estado brasileiro que historicamente nega 0 acesso às políticas sociais para a categoria dos pescadores artesanais e aos demais trabalhadores no município de Cametá e no Brasil como um todo, pois, como bem ilustra Arroyo (2002, p. 92), o trabalhador "nunca foi convidado a desfrutar dos prazeres da cultura e do cultivo das letras, das artes e do espírito".

Acreditamos que tais ações, circunscritas nos limites das necessidades imediatas, representam afirmação de interesses da classe trabalhadora, mesmo coexistindo com 0 interesse do sistema capitalista de não questionamento da ordem vigente de relações. Contudo, para que a práxis dos pescadores artesanais não se resuma aos limites da ordem sociometabólica do capital, é preciso que a Colônia Z-16 promova ações que avancem na contestação da objetividade vivida, inclusive experienciando modos outros de relações para além daqueles vinculados ao capital, como individualismo, consumismo, etc.

Novaes (2002) adverte que "[...] a integração de parcelas dos trabalhadores à sociedade de consumo de mercadorias descartáveis e à geração de emprego precário somente aprofundam a alienação dos trabalhadores" (p. 3). A partir disso, pontuamos que a Colônia Z-16 precisa traçar estratégias que objetivem o fortalecimento da organização política de classe dos pescadores artesanais. Assim, deve se utilizar de demandas imediatas da categoria para estruturar suas lutas, pois "de modo algum se

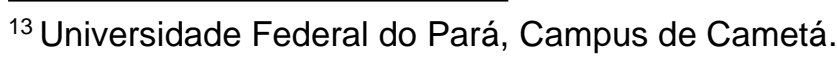


podem libertar os homens enquanto estes não estiverem em condições de adquirir comida, bebida, habitação e vestuário na qualidade e na quantidade perfeitas" (MARX \& ENGELS, op. cit., p. 35), mas isso não impede que, paralelamente se avance na compreensão das contradições do sistema do capital, na forma como essas contradições afetam os pescadores artesanais como classe e na contestação da ordem social de distribuição da riqueza desenvolvendo, paulatinamente, a consciência de classe-para-si ${ }^{14}$.

\section{CONSIDERAÇÕES FINAIS}

Do ponto de vista formal, historicamente, a formação dos trabalhadores é alienante e por isso os espaços coletivos de organização dos trabalhadores, como a Colônia de Pescadores Artesanais Z-16 de Cametá, fazem-se relevantes e necessários para a organização política e o entendimento da situação de exploração em que se encontram. Contudo, a pesquisa apontanos, nesse aspecto, para uma carência de acesso por parte dos pescadores artesanais a uma formação crítica que lhes forneça a compreensão da sua materialidade e a possibilidade de transformá-la, uma vez que os processos de formação que observamos se pautam na esfera do utilitarismo e do imediatismo.

As determinações da lógica capitalista, ao impor múltiplas necessidades para a sobrevivência dos pescadores artesanais, também dificultam a atuação desses sujeitos no sentido da contestação da ordem

\footnotetext{
${ }^{14}$ Rodrigues (2012, p. 79) destaca que Lukács (2003) “[...] tratando de questões relacionadas à consciência de classe, expõe que ela passa por dois momentos fundamentais no processo de sentido sobre a 'situação histórica de classe', consubstanciados numa consciência de classeem-si e numa consciência de classe-para-si". E ainda salienta que "inicialmente, em decorrência do processo de estruturação da propriedade privada, vê-se o surgimento da classe-em-si, quando, independente de consciência sobre a realidade fundada na relação capital-trabalho, os homens se postam em frontes diferentes pela própria natureza estruturante do capital. Nesse contexto, a consciência de classe não chegou a instaurar a ação organizada dos trabalhadores, ficando na constatação de que o mundo para uns é bom e para outros, mal" [...]. Todavia, no dizer de Lukács (2003, p. 184), "é preciso que os trabalhadores se tornem '[...] uma classe, como disse Marx, não somente 'em relação ao capital', mas 'para si mesmo'; isto é, elevar a necessidade econômica de sua luta de classe ao nível de uma vontade consciente, de uma consciência de classe ativa'. Aqui, a consciência alcança o status de uma práxis revolucionária, nos moldes propostos por Vázquez (1968), quando a unidade teórico-prática passa a orientar a atividade política dos trabalhadores, fornecendo-Ihes estratégias e táticas necessárias para suas disputas de classe".
} 
vigente, uma vez que os força a lutar pelo imediato, como no caso da implementação dos Acordos de Pesca, do acesso ao seguro defeso, aos financiamentos bancários, etc. Ademais, uma vez resolvidos os problemas imediatos do pescador artesanal, não há continuidade na luta em função da resolução daqueles problemas a partir de suas causas estruturais, nem 0 entendimento de tais problemas como sociais, isto é, que ocorrem para além do espaço da Colônia Z-16, mesmo que sob diversas formas de manifestação.

Nesse aspecto, os princípios de organização coletiva em busca de interesses coletivos estão sendo dominados pela objetividade das necessidades imediatas, transformando o que poderia se tornar consciência revolucionária em consciência imediata e/ou reformista que se objetiva como práxis utilitária de luta no campo imediato sem a contestação da ordem vigente de relações.

\section{Referências Bibliográficas}

ARROYO, Miguel. O direito do trabalhador à educação. In: GOMES, Carlos Minayo [et al.] Trabalho e conhecimento: dilemas da educação do trabalhador. $4^{\mathrm{a}}$ ed. São Paulo: Cortez, 2002.

BARDIN, L. Análise de conteúdo. Lisboa: Edições 70, 1997.

BARRA, José Domingos Fernandes. A relação trabalho e educação no contexto dos Acordos de Pesca em Cametá/PA: uma alternativa econômica ou uma prática de resistência? 2013. 116f. Dissertação (Mestrado em Educação) UFPA, Belém.

BOGO, Ademar. Identidade e Luta de Classes. 2. ed. São Paulo: Expressão Popular, 2010.

BRASIL. Ministério do Meio Ambiente. IBAMA. Instrução Normativa n 29 , de 31 de dezembro de 2002 . Disponível em: <www.ibama.gov.br/sophia/cnia/legislacao/IBAMA/IN0029-311202.PDF> Acesso em: 10 ago.2017.

KOSIK, Karel. A dialética do concreto - Tradução de Célia Neves e Alderico Toríbio. $2^{\underline{a}}$ ed. Rio de Janeiro: Paz e Terra, 1976.

LUKÁCS, Georg. História e consciência de classe: estudos sobre a dialética marxista. São Paulo: Martins Fontes, 2003. 
MARX, Karl \& ENGELS, Friedrich. A Ideologia Alemã. São Paulo: Expressão Popular, 2007.

MARX, Karl. Manuscritos econômico-filosóficos. Tradução, apresentação e notas Jesus Ranieri. 4ª reimpr. São Paulo: Boitempo, 2010.

O capital: crítica da economia política. $20^{\underline{a}}$ ed. Rio de Janeiro: Civilização brasileira, 2002, livro 1, 2 v.

MÈSZÁROS, I. Para além do capital. $1^{\underline{a}}$ ed. (revista). São Paulo: Boitempo, 2011.

NOVAES, Henrique T. A educação escolar e não escolar nas fábricas recuperadas. 2002. Mimeografado.

PÁDUA, Elisabete Matallo Marchesini. Metodologia da pesquisa: abordagem teórico-prática. 17ª ed. Campinas, SP: Papirus, 2012.

RODRIGUES, Doriedson do Socorro. Saberes Sociais e Luta de Classes: um estudo a partir da Colônia de Pescadores Artesanais Z-16 - Cametá-Pa. 2012. 337f. Tese (Doutorado em Educação) - UFPA, Belém.

VÁZQUEZ, Adolfo Sánchez. Filosofia da Práxis. 1aㅡ. ed. Buenos Aires: Consejo Latino americano de Ciencias Sociales - CLACSO; São Paulo: Expressão Popular, Brasil, 2007.

Recebido em: 22 de outubro de 2017. Aprovado em: 9 de janeiro de 2018. Publicado em: 31 de janeiro de 2018. 